Health Informatics - An International Journal (HIIJ) Vol.5, No.4, November 2016

\title{
IMPLEMENTING ELECTRONIC HEALTH RECORDS IN NEW ZEALAND: A CRITICAL APPRAISAL OF LITERATURE
}

\author{
Arun Sam Singh Selwyn Jebaraj \\ School of Health Sciences, University of Canterbury, Christchurch, New Zealand
}

\begin{abstract}
New Zealand health sector has increasing demands in theageing population and ongoing inflation of medical costs. These demands are growing, and the importance of technology could optimise the healthcare sector performance. Advancement in technology drives Electronic Health Records implementation to add substantial value to health delivery systems. The investment and promotion of health informationinfrastructure have positioned New Zealand as a world leader in the field of primary care sector. Factors such as organisation structure, culture, leadership and workflow design are important to achieving successful implementation of Electronic Health Records. This review intends to critically appraise the advantages of EHRs over paper-based records (PBRs). It outlines the measures introduced by Ministry of Health to implement EHRs across the health sector in New Zealand. Furthermore, the review will provide an international comparison in implementing EHRs with that of New Zealand.
\end{abstract}

\section{KEYWORDS}

Electronic Health Records, Paper Based Records, Health Records

\section{INTRODUCTION}

New Zealand health sector faces challenges due to escalating medical costs. This trend is likely to continue with the increasing demands from the ageing population and ongoing inflation of medical costs. The health demands are growing due to increasing shortage of health workforce and a declining labour productivity in the health sector (1).Technology could be an important determinant to optimise the healthcare sector performance.

Advancement in technology is a key driver for New Zealand to introduce Electronic Health Records (EHRs). Seamless integration of primary and secondary care health information is necessary to ensure high productivity of EHRs. Factors such as organisation structure, culture, leadership and workflow design are important to achieving successful implementation of EHRs. Therefore EHR implementation in health sector could add substantial value to the New Zealand healthcare delivery system (1).

\section{HEALTH RECORDS}

Records relate to any information and documents that are arranged in a systematic way, acting for the purpose of accountability and as a means of communication $(2,3)$. The origin of first known records in the health sector was reported by Hippocrates in Fifth century (4). Medical records relate to a systemic way of collecting, sorting and storing the required data, with the objective of reporting the information easily when required. For years, medical records were handwritten in papers, kept in files and maintained as patient-based records (3).

DOI: 10.5121/hiij.2016.5401 
Paper-Based Records (PBRs) are described as, “An account of a patient's health and disease after he or she has sought medical help. This record usually contains findings, considerations, test results and treatment information related to the disease process"(4). Paper records are used to collect the primary information from patients and then input the information into computers. These records are significant to any treatment, and should be stored safely and free from privacy risks (5). Factors including physician's handwriting, retrieval mechanical destruction of papers and retrieval time influenced PBRs could not be helpful for future and to a larger extent $(3,6)$. Uncertainty, fragmentation of information, and storage issues associated with bulky paper

records are some of the cited barriers associated with paper records which lead to the introduction of EHRs (7).

\section{DEFINITION OF ELECTRONIC HEALTh RECORDS (EHRs)}

The concept of EHR is also named as Electronic Patient Record (EPR), Electronic Medical Record (EMR) and Computerized Patient Record (CPR), National Health Record (NHR) (1). Health Information Management Systems Society (HIMSS) defined EHRs as, "a longitudinal electronic record of patient health information generated by one or more encounters in any care delivery setting" (8).

\section{BENEFITS OF USING EHRS}

Implementation of EHRs provides wider benefits to clinicians, patients, and healthcare managers as well as enhance healthcare delivery systems (3). Benefits of EHRs could be classified into clinical, organisational and societal outcomes. Improved quality of care and patient safety are the key clinical outcomes associated with using EHRs. Some reported advantages of EHRs include: a) improved legibility of clinical notes, b) accessible information, c) computerized reminders to physicians $(9,10)$, d) standardised care $(11)$, e) reduced clinical investigations(12), f) reduced medication errors, and g) low mortality rates associated with reduced medical complications (13). Ultimately, this has been shown to improve the quality and patient safety (14-16).

EHRs organisational outcomes relate to revenue enhancement, by reducing inaccurate coding, the costs associated with paper charts, and documentation procedures. It also enhances data security and patient confidentiality (17-19). EHRs societal benefits facilitate the ability to conduct research with patient data and identifies evidence-based clinical practices $(20,21)$. Several healthcare institutions use PBRs to collect the primary patient information and then subsequently fed them into computers, and thereby use both PBRs and EHRs (22).

\subsection{Advantages of using EHRs over PBRs}

Patient-based records provide significant attributes as physical and information systems and are easy to carry, but these are overcome by small portable tablets. PBRs need no special training when compared to use EHRs by existing healthcare professional. The need to overcome such disadvantages has led to the development of EHRs (4).

The structured text and controlled vocabulary of EHRs (22), allows faster retrieval of information. It does not require a person to pull the records when needed and could integrate, share information to improve the documentation as compared to standalone PBRs (14, 23-26). PBRs limit the access of health information to a geographic location, but EHRs could help to identify the inappropriate access of health information (27). Integration of information, medical 
advancements, upcoming retrospective research significantly contribute organisations to the use of EHRS over PBRs (28).

The availability of integrated health information and the ease of access facilitate benefits, but also pose challenges in implementing EHRs. The cost associated with implementation, converting paper charts to electronic one, and the maintenance work associated with software up-gradation, ongoing training support needs are the reported barriers to successfully implement EHRs (29-31). Furthermore, disruption of the normal workflow, temporary loss of productivity and increased the risk of patient privacy violations, lack of interoperability standards between EHRs also poses the challenge to successfully implement EHRs $(15,32,33)$. The emergence of new standards for exchanging, integrating, sharing and retrieving information has facilitated implementing EHRs globally including New Zealand.

\section{IMPLEMENTATION OF EHRS IN NEW ZEALAND}

In New Zealand, General Practitioners (GPs) were the first to use computers in the early 1980s(27). In 1992 Ministry of Health introduced National Health Identifier (NHI). It is a unique identifier assigned to every person who uses health and disability support services in New Zealand to make an error- free identification $(4,27,34)$. This NHI is associated to Medical warnings System (MWS), that warns health professional about any risk factors when making a clinical decision with an individual patient $(34,35)$. Every health provider is uniquely identified by Health Provider Index (HPI) to enable secure ways to access and transfer health information (36).

Transferring and storing health information electronically was introduced by Health Link in 1993 (37). This is a health-system integrator that enables medical practitioners to communicate electronically with other health systems. $(37,38)$. This enabled GPs to exchange electronic information using the point-2- point communication and computerized nearly $100 \%$ of primary care in New Zealand $(1,38)$. The rules to collect, use and disclose this information is governed by Health Information Privacy Code 1994 (39). The clear importance of this technology was established by the formation of Information Health Strategy in 1991, and Health Information Strategy in 2000 (4). In 2003, Child Health Information strategy (CHIS) plan was developed to collect and use the health information of children and young people (40).

This technology importance was further enhanced by the establishment of the National Health Information Standards Organisation (HISO) in 2003. HISO supports to develop and manage technology standards such as Health Level seven (HL7), to enable an integrated healthcare in New Zealand (41). Systematized Nomenclature of Medicine- Clinical terms (SNOMED CT) an essential clinical terminology standard had been endorsed by HISO to be used across the health and disability sector in New Zealand $(38,42)$.

Initiatives such as NHI, HPI, MWS, a National clinical terminology, early adoption of HL7, and the National health information privacy code provided the building blocks for the National EHR implementation (43). EHR architecture shares information, either on a need-to-know basis or limits data access to providers within the "circle of care" $(41,44)$. Some of the well-functioning regional EHRs are Primary Information Systems Management (PRISM) implemented by West Coast District Health Board (DHB) and TesSafe project implemented between Auckland DHBs of Waitemata, Auckland, and Counties Manukau(45). Nigel Murray, CEO of Waikato DHB, highlighted consumer as the key to designing the single National EHR to turn data into meaningful information (46). This single EHR could consolidate information to improve decision support and patient care coordination for patients with chronic health conditions (47). 
Health Informatics - An International Journal (HIIJ) Vol.5, No.4, November 2016

\section{Challenges aCROSS OTHer COUNTRIES}

Countries such as the United Kingdom (UK), Australia, Canada have invested heavily, however, they are yet to successfully achieve National Health IT solutions for their people (48). The United States of America (USA), uses an incentive program named "Meaningful use of electronic record" to implement EHRs. To receive this financial incentive, organisations need to demonstrate that EHRs implementation improves the health outcomes and quality of care (27). In 1998 New Zealand government provided a one-time grant to GPs to purchase computers and make electronic claims. This grant helped $98 \%$ of GPs to use computerized billing systems (1). The United Kingdom identifies a unique patient master index as a national requirement for implementing EHRs (49). This unique identifier number was resisted by the United States of America as it compromises on patient privacy. These concerns were not foreseen in New Zealand and created a strong capability for integrating different information platforms by developing unique identifiers like NHI and HPI $(1,27)$.

Effective implementation of EHRs needs vocabulary, messaging and security standards to exchange information seamlessly. Many countries have adopted standards such as International Standards Organisation (ISO), HL7, to enable interoperability in exchanging information. In New Zealand, these standards are based on ISO models in exchanging information. Canada Health Infoway programme used the Picture Archiving Communication System (PACS) for capturing and transmitting images electronically and showed improved efficiency in clinical decision making (1). In New Zealand, all DHBs have adopted filmless radiology department, either by implementing radiology PACS or receive and secure electronic radiology images from a third party vendor within their electronic medical records (50).

Moving towards a single EHR system, Singapore's National Electronic Health Record (NEHR) relates to the goal of "One Singaporean, One Health Record" for its 5.1million citizens (Deloitte, 2015). In New Zealand, Health Minister Jonathan Coleman stated, the single National EHR would provide information via patient portals and enable clinicians to get comprehensive patient information in one place. It would also enable the government to make better investment decisions, target and monitor the effectiveness of public health programmes (Scoop media, 2016 June 21).

Protection and sharing of this electronic medical information in the USA are directed by Health Insurance Portability and Accountability Act (HIPAA). In New Zealand, the Privacy act 1993 and Health Information Privacy code 1994, governs the collection, usage, and disclosure of medical information (27). The National Health IT Board established Connected Health Programmes, to share secure health information between health professionals (27).

The DHBs in New Zealand have their decisions in IT investments. The focus on IT infrastructure and legacy systems maintenance contributes to 40 to $60 \%$ of the total IT spending (Deloitte, 2015). The "Working to Add Value of E- information (WAVE) reported the investment and promotion of health information infrastructure have positioned New Zealand as a world leader in the field of primary care sector (43). Consistent, multi- year level funding needs to address IT investment into strategic assets, rather than subject to short-term constraint (51). The Thirty year New Zealand Infrastructure Plan 2015 provides, a better approach to use the existing infrastructure and allocating resources for new investment (52). There is also a need for DHBs to use structured templates for documentation, implementing nursing documentation systems and support to implement medication safety management to move up current Electronic Medical Record Adoption Model (EMRAM) score of 2.8(50). 
Health Informatics - An International Journal (HIIJ) Vol.5, No.4, November 2016

\section{CONCLUSION}

The investment and promotion of health information infrastructure have positioned New Zealand as a world leader in the field of primary care sector. But a system-wide approach to managing the electronic health information across the health sector is currently in early stages in New Zealand. Despite having unique identifiers such as NHI and HPI, it remains a challenge to merge data from different systems and aggregate into useful information. This relates to poor data quality and reduced patient outcomes as it lacks management, reporting, and analytical capabilities. Some of the regional and national initiatives that consolidate the information offers a promising prospect for further consolidating the information. This could progress the ability to integrate the health information to implement the single EHR system at New Zealand. The welldeveloped electronic medical record foundation in New Zealand puts it on par with the majority of the countries across the world. Leadership and the governance models could standardise the clinical workflow and would contribute towards a successful implementation of single national EHR. Such an implementation could improve decision support and foster patient care coordination for the health and wellbeing of citizens in New Zealand.

\section{REFERENCES}

[1] Deloitte. Independent review of New Zealand's Electronic Health Records Strategy 2015 [Available from:http://www.nzdoctor.co.nz/media/6000178/independent-review-new-zealandelectronic-health-records-strategy-oct15.pdf.

[2] Ivanova M, Ivanov S, Magnini VP. The Routledge Handbook of Hotel Chain Management: Routledge; 2016.

[3] Alsahafi YA. Studies of EHR implementation and operation in different countries with particular reference to Saudi Arabia: a thesis presented in partial fulfillment of the requirements of degree of Master in Information Science at Massey University, Albany campus, Auckland, New Zealand: Massey University; 2012.

[4] Mharakurwa Hwata E. The Attitudes that New Zealand Chinese and Korean people have toward sharing their health information in Electronic Health Records in Christchurch. 2014:15.

[5] Chassin MR, Galvin RW. The urgent need to improve health care quality: Institute of Medicine National Roundtable on Health Care Quality. Jama. 1998;280(11):1000-5.

[6] Kohn L, Corrigan J, Donaldson M. To err is human: building a safer health system. National Academy of Science, Institute of Medicine. 2002.

[7] Stockman J. Paper Versus Computer: Feasibility of an Electronic Medical Record in General Pediatrics Roukema J, Los RK, Bleeker SE, et al (Sophia Children's Hosp, Rotterdam, The Netherlands) Pediatrics 117: 15-21, 2006. Year Book of Pediatrics. 2007;2007:302-3.

[8] HIMSS. Electronic Health Records [Available from: http://www.himss.org/library/ehr/.

[9] Demakis JG, Beauchamp C, Cull WL, Denwood R, Eisen SA, Lofgren R, et al. Improving residents' compliance with standards of ambulatory care: results from the VA Cooperative Study on Computerized Reminders. Jama. 2000;284(11):1411-6.

[10] McDonald C, Hui SL, Tierney WM. Effects of computer reminders for influenza vaccination on morbidity during influenza epidemics. MD computing: computers in medical practice. 1991;9(5):304-12.

[11] Tierney WM, Hui SL, McDonald CJ. Delayed feedback of physician performance versus immediate reminders to perform preventive care: effects on physician compliance. Medical care. 1986:659-66. 
[12] Wilson GA, McDonald CJ, McCabe Jr GP. The effect of immediate access to a computerized medical record on physician test ordering: a controlled clinical trial in the emergency room. American Journal of Public Health. 1982;72(7):698-702.

[13] Amarasingham R, Plantinga L, Diener-West M, Gaskin DJ, Powe NR. Clinical information technologies and inpatient outcomes: a multiple hospital study. Archives of internal medicine. 2009;169(2):108-14.

[14] Hoyt's DRE. Benefits of switching to an electronic health record n.d. [Available from: http://www.practicefusion.com/health-informatics-practical-guide/.

[15] Palma G. Health Information Technology 2013 October 14 [Available from: http://www.beckershospitalreview.com/healthcare-information-technology/electronic-healthrecords-the-good-the-bad-and-the-ugly.html.

[16] McDonald CJ, Hui SL, Smith DM, Tierney WM, Cohen SJ, Weinberger M, et al. Reminders to physicians from an introspective computer medical record: a two-year randomized trial. Annals of Internal Medicine. 1984;100(1):130-8.

[17] Agrawal A. Return on investment analysis for a computer-based patient record in the outpatient clinic setting. Journal of the Association for Academic Minority Physicians: the official publication of the Association for Academic Minority Physicians. 2002;13(3):61-5.

[18] Mildon J, Cohen T. Drivers in the electronic medical records market. Health management technology. 2001;22(5):14.

[19] Virapongse A, Bates DW, Shi P, Jenter CA, Volk LA, Kleinman K, et al. Electronic health records and malpractice claims in office practice. Archives of internal medicine. 2008;168(21):2362-7.

[20] Aspden P, Corrigan JM, Wolcott J, Erickson SM. Patient safety: achieving a new standard for care: National Academies Press; 2004.

[21] Kukafka R, Ancker JS, Chan C, Chelico J, Khan S, Mortoti S, et al. Redesigning electronic health record systems to support public health. Journal of biomedical informatics. 2007;40(4):398-409.

[22] Stausberg J, Koch D, Ingenerf J, Betzler M. Comparing paper-based with electronic patient records: lessons learned during a study on diagnosis and procedure codes. Journal of the American Medical Informatics Association. 2003;10(5):470-7.

[23] Eden KB, Messina R, Li H, Osterweil P, Henderson CR, Guise J-M. Examining the value of electronic health records on labor and delivery. American journal of obstetrics and gynecology. 2008;199(3):307. e1-. e9.

[24] Howe SE, Nagel DC, Chen C-c, Griffin SM, Lightbourne J, Warnick WL, editors. The president's information technology advisory committee's february 2001 digital library report and its impact. Proceedings of the 1st ACM/IEEE-CS joint conference on Digital libraries; 2001: ACM.

[25] Smith PC, Araya-Guerra R, Bublitz C, Parnes B, Dickinson LM, Van Vorst R, et al. Missing clinical information during primary care visits. Jama. 2005;293(5):565-71.

[26] Tang PC, LaRosa MP, Newcomb C, Gorden SM. Measuring the effects of reminders for outpatient influenza immunizations at the point of clinical opportunity. Journal of the American Medical Informatics Association. 1999;6(2):115-21.

[27] Bensley E. Shared Electronic Health Records.

[28] Coiera E. Healthcare terminologies and classification systems. Guide to Health Informatics, Hodder Arnold. 2003:201-16.

[29] Fleming NS, Culler SD, McCorkle R, Becker ER, Ballard DJ. The financial and nonfinancial costs of implementing electronic health records in primary care practices. Health Affairs. 2011;30(3):481-9. 
Health Informatics - An International Journal (HIIJ) Vol.5, No.4, November 2016

[30] Menachemi N. Barriers to ambulatory EHR: who are'imminent adopters' and how do they differ from other physicians? Journal of Innovation in Health Informatics. 2006;14(2):101-8.

[31] Schmitt KF, Wofford DA. Financial analysis projects clear returns from Electronic Medical Records: Demonstrating the economic benefits of an electronic medical record is possible with the input of staff who can identify the technology's benefits. Healthcare Financial Management. 2002;56(1):52-8.

[32] Westin AF. Public attitudes toward electronic health records. AHIP Cover. 2005;46(4):22-5.

[33] Zurita L, Nøhr C. Patient opinion--EHR assessment from the users perspective. Studies in health technology and informatics. 2003;107(Pt 2):1333-6.

[34] Ministry of Health. National Health Index 2012 May 10 [Available from: http://www.health.govt.nz/our-work/health-identity/national-health-index.

[35] Ministry of Health. National Medical Warning System 2012 March 15 [Available from: http://www.health.govt.nz/our-work/health-identity/national-medical-warning-system.

[36] Ministry of Health. Health Provider Index 2016 April 04 [Available from: http://www.health.govt.nz/our-work/health-identity/health-provider-index.

[37] Health Link. About us n.d. [Available from: https://www.healthlink.net/en_NZ/about-us/.

[38] Protti D, Bowden T. Electronic medical record adoption in New Zealand primary care physician offices. Commonwealth Fund. 2010;96:1-13.

[39] Hunter I, editor Patient attitudes to electronic medical records. Proceedings of Privacy Forum, New Zealand; 2002.

[40] Ministry of Health. Child Health Information Strategy 2003 April 02 [Available from: http://www.health.govt.nz/publication/child-health-information-strategy.

[41] Terry NP, Francis LP. Ensuring the privacy and confidentiality of electronic health records. U Ill L Rev. 2007:681.

[42] Ministry of Health. About SNOMED CT 2011 July [Available from: http://www.health.govt.nz/nz-health-statistics/classification-and-terminology/new-zealandsnomed-ctr-national-release-centre/about-snomed-ctr.

[43] King A. Launch of the WAVE report 2001 October 29 [Available from: https://www.beehive.govt.nz/speech/launch-wave-report.

[44] Pullar T. E-health records in Government's sights again after 2014 target missed. Stuff Business day. 2015 October 21.

[45] Scoop media. Jonathan Coleman Healthcare Congress speech, Auckland 2016 June 21 [Available from: http://www.scoop.co.nz/stories/PA1606/S00361/jonathan-coleman-healthcarecongress-speech-auckland.htm.

[46] National Health IT Board. Design workshop progresses on consumer-centric EHR 2016 April [Available from: http://healthitboard.health.govt.nz/health-it-programme-2015-2020-0/designworkshop-progresses-consumer-centric-ehr.

[47] Topham L. Grand plan to develop a single national electronic health record for Kiwis 2015 October 20 [Available from: http://www.nzdoctor.co.nz/news/2015/october-2015/20/grand-planto-develop-a-single-national-electronic-health-record-for-kiwis.aspx.

[48] Osborne G. National Health IT Board and eHealth IT adoption in New Zealand 2014 May [Available from: http://www.healthshare.health.nz/docs/default-source/board-workshop/day-21330---graeme-osborne---national-health-it-board.pdf?sfvrsn=0.

[49] Mason MK. What Can We Learn from the Rest of the World? a look at international electronic health record best practices. Canada Health Infoway Report Retrieved March. 2004;1:2010. 
Health Informatics - An International Journal (HIIJ) Vol.5, No.4, November 2016

[50] National Health IT Board. EMRAM Assessment for DHB digital maturity 2016 July [Available from: http://healthitboard.health.govt.nz/health-it-programme-2015-2020-0/emram-assessmentdhb-digital-maturity.

[51] Ministry of Health. National Health IT Plan Update 2013/14 2013 [Available from: https://healthitboard.health.govt.nz/system/files/documents/publications/national-health-it-planupdate-2013-14-nov13.pdf.

[52] National Infrastructure Unit. Thirty year New Zealand infrastructure plan 20152015 [Available from: http://www.infrastructure.govt.nz/plan/2015/.

\section{Author}

\section{Short Biography}

Arun Sam Singh Selwyn Jebaraj. BPT, MBA- Hospital and Health Systems Management, PG Diploma Health Information Management. 8 years of Experience into Hospital Operations Management, Quality and Information Management. Lean Six Sigma Green Belt Certified Professional. 